\title{
Atendimento humanizado: as concepções de estudantes de Medicina
}

\author{
Vitória Batista Calmon de Passos (D) \\ Universidade Federal da Bahia - Salvador (BA) - Brasil \\ Renata Meira Véras (iD \\ Universidade Federal da Bahia - Salvador (BA) - Brasil \\ Clara Couto Fernandez (iD \\ Universidade Federal da Bahia - Salvador (BA) - Brasil \\ Odonilton Lima Lemos (iD \\ Universidade Federal da Bahia - Salvador (BA) - Brasil \\ Gustavo Marques Porto Cardoso iD \\ Faculdade Nobre de Feira de Santana - Feira de Santana (BA) - Brasil \\ Marcelo Nunes Dourado Rocha \\ Universidade Federal da Bahia - Salvador (BA) - Brasil
}

\section{RESUMO}

Objetivo: O presente artigo objetiva analisar as concepções de atendimento médico humanizado de graduandos em Medicina da Universidade Federal da Bahia. Métodos: Para o estudo foi realizada uma investigação qualitativa. Os dados foram produzidos a partir de um questionário individual com questões abertas, aplicados a estudantes do $1^{\circ}$ ao $8^{\circ}$ semestres do curso de Medicina, em agosto de 2018 ( $n=451$ ). Resultados: A partir da análise de conteúdo das respostas identificou-se que parte dos estudantes conceitua o atendimento humanizado orientando-se principalmente por aspectos gerais da Política Nacional de Humanização, outros demonstraram superar essa percepção ao relatarem aspectos de sensibilidade e empatia; enquanto um terceiro grupo, por sua vez, apresentou concepções que vão de encontro à proposta do conceito de humanização, reforçando, dessa forma, o discurso de superioridade médica. Conclusão: Ficou evidente que os estudantes de Medicina investigados conceituam atendimento humanizado a partir de orientações diversas, demonstrando que múltiplos fatores podem contribuir para essas concepções.

Descritores: Humanização; Humanização da Assistência; Humanização dos Serviços; Educação médica; Estudantes de medicina; Universidade.

\section{INTRODUÇÃO}

No cotidiano dos serviços de saúde, são frequentes as reclamações dos pacientes acerca da falta de empatia, de atenção e de escuta por parte daqueles que são os mediadores do seu processo de cura. Esse cenário evidencia um paradoxo que existe entre a concepção de cuidado que deveria nortear a prática dos médicos e demais profissionais e a "falta de cuidado" que se configura enquanto uma das principais queixas dos usuários desses serviços ${ }^{(1)}$. Tal paradoxo aponta para um denominador comum que é a desumanização dos serviços e das práticas de saúde (2).

$\mathrm{Na}$ contemporaneidade, os avanços científicos-tecnológicos promoveram cada vez mais a especialização do profissional médico. Com isso, a fim de acompanhar esses avanços, a formação médica tornou-se fragmentada, supervalorizando os saberes técnicos-científicos em detrimento das competências ético-relacionais e intersubjetivas ${ }^{(3)}$.

Relações e práticas médicas consideradas "desumanizadas", contudo, só foram eleitas objeto de estudo sistemático da sociologia médica a partir da década de 70 e tiveram como grandes nomes Geiger e Howard. No Brasil, as reflexões acerca do tema humanização obtiveram maior destaque também a partir de 1970 com o apoio do movimento sanitário e do movimento feminista às pautas de direitos sexuais e reprodutivos em uma perspectiva

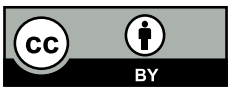


crítica ao modelo médico hegemônico ${ }^{(4)}$. Entretanto, o debate em torno da humanização só entrou efetivamente na agenda política no ano 2000, a partir de iniciativas de algumas secretarias municipais e estaduais de saúde, somente passando a ter uma abrangência nacional com o Programa Nacional de Humanização da Assistência Hospitalar (PNHAH) ${ }^{(5)}$.

Em 2003 foi publicada a Política Nacional de Humanização (PNH) adotando como princípios teóricos-metodológicos: o protagonismo dos sujeitos coletivos, a indissociabilidade entre atenção e gestão e a transversalidade ${ }^{(6)}$, ampliando-se assim o campo da assistência hospitalar aos serviços suplementares de atenção à saúde. A adoção destes princípios deram início às discussões acerca do acolhimento, da importância do diálogo e da conversa, ganhando enquadramentos teóricos à luz da filosofia, sociologia médica, psicologia e psicanálise e sendo vistos como estratégicos na produção de cuidados em saúde ${ }^{(4,7-9)}$.

No que tange a formação em saúde, em especial a formação em medicina, a predominância do modelo técnico-cientíico na formação profissional se ampliou, baseada nas demandas do mercado e da globalização( ${ }^{(10)}$. Tal conduta é apontada por diversos autores como uma das causas do processo de desumanização dos atendimentos ${ }^{(1,11)}$.

Considerando-se tudo isso, visando a adoção de práticas de cuidado em saúde mais humanizadas, a PNH surgiu principalmente com o objetivo de promover uma mudança no cenário vigente de hipervalorização do modelo técnico-científico da saúde, e desde então tem atuado incentivando o desenvolvimento de atitudes humanísticas entre os profissionais, nos eixos da gestão, da atenção em saúde e da formação. Essa política se fundamenta, portanto, na superação do reducionismo ao qual a racionalidade biomédica está aprisionada, tornando o encontro com o outro imprescindível(12). No entanto, embora o conceito de humanização se constitua num alicerce para diversos programas e políticas, ele carece de uma definição mais clara, já que se conforma mais como uma diretriz de trabalho do que como um aporte teórico-prático ${ }^{(4)}$. Como não existe uma única definição teórica e operacional para o termo humanização, ele se tornou polissêmico. Consequentemente, essa polissemia tem como resultado a falta de demarcação de sua abrangência e aplicabilidade ${ }^{(4)}$. Assim, alguns autores ${ }^{(13,14)}$ têm destacado a necessidade de discutir tal conceito desde a formação acadêmica, visto que compreender o que é a humanização irá refletir diretamente na prática clínica e desenvolver o relacionamento médico-paciente.

Em uma investigação ${ }^{(15)}$ sobre os conceitos de humanização comumente empregados na literatura nos últimos anos, as autoras identificaram que os principais sentidos aos quais esse termo é atribuído são o de ética dos relacionamentos, do cuidado e da comunicação com o outro, o de pensar sobre o tema como um conceito que orienta práticas; e de reflexões a respeito do que a humanização produz. Outra pesquisa encontrou ${ }^{(6)}$ os sentidos relacionados à empatia, diálogo, respeito às diferenças para definição de humanização. Já outro estudo( ${ }^{(16)}$ identificou a definição de humanização como 'bom humano' orientado pelas exigências de mercado para garantia de qualidade do serviço. Essa polissemia reforça a importância dos estudantes de medicina, compreenderem a ideia de atendimento médico humanizado sob múltiplas perspectivas, para atuar de maneira mais efetiva no Sistema Único de Saúde (SUS).

Reconhece-se que humanizar a atenção à saúde é um processo a longo prazo que está intimamente ligado a contextos que se apresentam dinâmicos e complexos. Nesse processo ocorrem resistências por parte dos atores envolvidos, pois a humanização requer mudanças de comportamentos historicamente construídos, principalmente em ambientes conservadores como o curso médico ${ }^{(17)}$.

Assim, coloca-se um desafio para o Estado brasileiro: orientar a formação destes médicos, desde o momento inicial até a educação permanente, estimulando que o cuidado à população seja de maneira humanizada, valorizando a integralidade e a promoção da saúde, como preconizado nos documentos oficiais ${ }^{(18,19)}$.

Dessa forma, são evidenciadas várias atribuições que compreendem práticas humanizadas de cuidado, tais quais a responsabilidade social, respeito e defesa da dignidade humana e da saúde integral do ser humano. Em um estudo ${ }^{(2)}$ a respeito dos perfis dos profissionais de saúde tendo as DCN como base, é revelado que para a construção de um conceito ampliado da saúde na formação dos profissionais desse campo, é necessária uma permanente articulação entre o SUS e o sistema de educação superior buscando suprir as necessidades de saúde da população. A humanização, nesse contexto, se mostra como um dos mais importantes fatores a ser contemplado por esse processo.

Nesse sentido, no âmbito da formação profissional em saúde, a publicação, em 2001, das Diretrizes Curriculares Nacionais (DCN) para o curso de medicina e sua revisão em 2014 contribuíram para um maior investimento na formação médica, buscando-se uma melhor adequação dos perfis profissionais aos princípios e diretrizes do SUS ${ }^{(21)}$.

Como consequência, diversas instituições têm promovido reformas curriculares inserindo componentes que visam garantir uma formação ética humanística aos estudantes. Em consonância com essas mudanças, a Faculdade de Medicina da Universidade Federal da Bahia (UFBA), aprovou um novo projeto pedagógico contemplando um eixo 
ético-humanístico que perpassa os primeiros oito semestres de formação médica e tem como objetivo desenvolver atitudes éticas e humanas, integrando todas as práticas curriculares ${ }^{(22)}$. A partir destas mudanças torna-se necessário investigar quais as concepções de atendimento médico humanizado foram construídas pelos estudantes de medicina da UFBA para se analisar como esses futuros profissionais pretendem atuar à luz das novas exigências profissionais.

O presente artigo objetiva analisar as concepções de atendimento médico humanizado de graduandos em Medicina da Universidade Federal da Bahia. Atrelado a isso, discute-se também sobre a contribuição da educação médica para a construção desses sentidos em consonância com a Política Nacional de Humanização.

\section{MÉTODOS}

Esse estudo trata-se de uma pesquisa qualitativa(23) de caráter exploratório( ${ }^{(24)}$ com recorte transversal(25). Importante ressaltar que este é parte de uma pesquisa mais ampla intitulada "O eixo ético-humanístico na Faculdade de Medicina da Bahia: percepções dos estudantes". Reforça-se que o objetivo da investigação foi analisar como os estudantes da graduação em Medicina da UFBA concebem o que é um atendimento médico humanizado.

Os dados da pesquisa foram produzidos com a aplicação individual de questionário aos estudantes do $1^{\circ}$ ao $8^{\circ}$ semestres do curso de Medicina da UFBA, por 4 examinadores, em sala de aula, durante os encontros das disciplinas de Ética que integra o eixo ético-humanístico do currículo, em agosto de 2018. Dos 1023 estudantes regularmente matriculados entre o primeiro e oitavo semestre do curso de Medicina da UFBA, 451 (44\%) responderam ao questionário.

$\mathrm{O}$ instrumento foi organizado em três partes. A primeira contemplou questões de assinalar referentes às características sóciodemográficas dos participantes, o que permitiu a análise por idade, sexo, raça, renda familiar, etc. A segunda parte requereu respostas numa escala do tipo Likert de cinco pontos sobre as percepções dos estudantes acerca do eixo ético-humanístico. Por fim, a terceira parte era constituída por duas questões abertas, no intuito de se analisar as contribuições do eixo ético-humanístico para a formação em medicina e as concepções de atendimento humanizado dos estudantes.

Especificamente neste estudo, o foco foi a última questão aberta da terceira parte do questionário: "O que é um atendimento médico humanizado para você?". Sobre a análise de questões abertas ${ }^{(26)}$, a literatura afirma que esta metodologia de produção de dados é interessante por favorecer respostas que denotam uma "compreensão espontânea" dos sujeitos sobre o objeto da investigação. Dessa maneira, a análise das respostas dessa questão, alinhada com as informações da literatura científica sobre os conceitos de humanização, se dispõe a vislumbrar os sentidos construídos pelos estudantes de Medicina da UFBA a respeito da humanização do atendimento. A análise de conteúdo temática ${ }^{(27)}$, foi escolhida como o método mais pertinente de análise do material coletado.

Do ponto de vista operacional, os procedimentos envolveram três etapas distintas, porém articuladas. A primeira fase consistiu na pré-exploração do corpus selecionado para análise, na qual sucederam-se várias leituras do material a fim de organizar informações importantes para as demais etapas ${ }^{(28)}$. Na segunda etapa ocorreu a seleção das unidades de análise a fim de realizar a análise temática das respostas dos estudantes e o processo de categorização não-apriorística dos elementos identificados nessas unidades. Ainda nessa fase, a partir da leitura do material selecionado, foram agrupadas aquelas unidades que apresentavam temática similar ${ }^{(28)}$. Dessa maneira, construíram-se três categorias: a) Concepção de atendimento médico humanizado de acordo com aspectos gerais que norteiam a PNH; b) Compreensão ampliada do conceito de Humanização; e, c) Conhecimento superficial do tema e tendência à valorização do modelo técnico-científico de atenção e da ideia de superioridade médica. Finalmente, na terceira e última etapa ocorreu o processo de análise propriamente dito, a partir do tratamento e interpretação dos dados categorizados à luz do referencial teórico do estudo ${ }^{(28)}$. Terminados os processos de categorização e análise, foram selecionadas algumas falas representativas das demais para elucidar a discussão de cada categoria.

O estudo obedeceu aos padrões éticos estabelecidos pela Resolução 466/12 e foi aprovado pelo Comitê de Ética em Pesquisa da Escola de Enfermagem da UFBA sob Parecer n. ${ }^{\circ} 2.769 .003$.

\section{RESULTADOS E DISCUSSÃO}

A média de idade dos 451 respondentes foi de 23 anos. Quanto ao sexo biológico, 50,7\% (193 respondentes) se identificaram como do sexo feminino. Por autodeclaração, uma maioria $(52,8 \%)$ se afirmou parda, seguidos por $32 \%$ autodeclarados brancos. O tipo de ensino médio prevalente foram escolas privadas com $55,6 \%$ (equivalente a 212 respondentes). A renda familiar com maior número de declarações esteve entre 10 e 30 salários mínimos, 
totalizando $31,2 \%$ das respostas. E finalmente, quanto à intenção de fazer uma especialização após a conclusão da graduação, a maioria absoluta $(98,4 \%)$ declarou concordar com essa afirmação. Clínica médica e cirurgia foram as áreas de maior interesse.

Um perfil socioeconômico elevado e uma preferência pela prática especializada da medicina são características comuns entre os estudantes desse curso, algo evidenciado em outros estudos. No entanto, uma maioria feminina e parda é algo diferente do padrão apontado nos estudos de perfil de estudantes de medicina, os quais têm sua maioria composta por homens autodeclarados brancos ${ }^{(29-31)}$. Essa diferença pode estar diretamente relacionada à efetividade das políticas de ações afirmativas implantadas na educação superior nos últimos anos, que buscam corrigir a histórica exclusão de algumas minorias no processo de escolarização e acesso ao ambiente universitário ${ }^{(32)}$.

As respostas analisadas que compuseram a primeira categoria foram aquelas que demonstraram concepções de humanização considerando aspectos gerais da $\mathrm{PNH}$, ao apontar, por exemplo, conceitos como ética profissional e dignidade humana. Segundo essa política, humanização pode ser considerada uma prática social capaz de ampliar vínculos, sobretudo os de solidariedade e de co-responsabilidade. Sendo, portanto, uma maneira de se promover inclusão(33).

Nesse sentido, tal inclusão se refere essencialmente a viabilizar a participação dos sujeitos e coletivos, sejam usuários ou profissionais, nos diversos cenários em que se organiza a saúde: a gestão, o cuidado e a formação. Essa integração, então, favorece a criação de bons vínculos e estimula a autonomia dos envolvidos ${ }^{(33)}$. Contudo, tendo isso em vista, chamou atenção o fato dos estudantes que compuseram esta categoria não transcenderem o que a PNH propõe, porque em suas respostas não demonstraram reflexão crítica a respeito do conceito e/ou não expuseram visões ampliadas do mesmo. As respostas agrupadas nessa categoria apenas reproduzem afirmações gerais e superficiais da política, como no destaque a seguir:

"O atendimento médico humanizado é ouvir." (Estudante 08, $8^{\circ}$ semestre)

"Um atendimento que, no mínimo, respeite a dignidade humana do paciente e os princípios éticos da profissão." (Estudante $369,2^{\circ}$ semestre)

"Que siga o exposto na PNH." (Estudante 428, $5^{\circ}$ semestre)

"Atendimento médico humanizado é um atendimento de humano para humano." (Estudante 414, $2^{\circ}$ semestre)

É importante afirmar que entender a PNH e o conceito de humanização que ela propõe é fundamental para todos os profissionais de saúde, sobretudo aqueles que estão em formação. A partir da compreensão do real sentido de humanizar haverá uma prática clínica ideal, para tanto, é necessário enxergar a medicina como uma atividade social e moral ${ }^{(34)}$. Entretanto, ir além do que está exposto na política indica que os estudantes que o fazem, futuros trabalhadores da saúde, compreendem a essência do que ela propõe e apresentam ainda uma criticidade maior quanto ao sentido de humanizar o atendimento. Humanizar a saúde, por sua vez, seria então estimular o desenvolvimento de características como respeito, valorização do outro e empatia nos profissionais. Corroborando com isso, é sabido que existem diversos conhecimentos, atitudes e habilidades, em múltiplos sentidos, que podem se configurar "traços humanísticos"(35). Dessa forma, um atendimento humanizado seria aquele que considerasse esses múltiplos fatores - que estão expostos na política - mas que também valorizasse as subjetividades dos profissionais e dos pacientes nesse processo.

As falas analisadas classificadas na segunda categoria, em contrapartida a isso, apontaram concepções ampliadas de humanização, especialmente, por demonstrarem além do entendimento dos aspectos preconizados pela $\mathrm{PNH}$, a capacidade de empatia pelos usuários dos serviços e compreensão a respeito de aspectos sensíveis do processo de atendimento:

"Médico que ouve o paciente, não interrompe, não é arrogante, se importa além da doença, respeita a autonomia (não faz procedimentos sem consentimento), não trata o paciente como mero cliente e que não impõe uma relação de superioridade." (Estudante 444, $5^{\circ}$ semestre)

"Um atendimento sem pressa, que o médico olha no olho do paciente. Que o médico passa a mensagem que o mais importante é o bem estar do paciente, e que este tem liberdade para falar de tudo, dúvidas, medos e sonhos. Atendimento que o médico não se empolga com doenças raras porque isso cresce o ego dele." (Estudante $437,5^{\circ}$ semestre)

"Um atendimento médico humanizado é o que visa entender o outro como um ser plural, não só pela sua patologia, mas que tem anseios, sentimentos, vivências e merece todo o respeito e cuidado individual dentro de sua pluralidade." (Estudante $385,5^{\circ}$ semestre) 
Acerca da empatia, acredita-se que seu significado estaria no sentido de um indivíduo perceber a realidade do outro como se fosse sua, mas sem nunca esquecer dessa noção de "como se", que significa compreender e respeitar essa realidade, mas ter em mente também as diferenças inerentes a cada um. Significa sensibilizar-se pelas necessidades e demandas dos sujeitos, entendendo suas particularidades ${ }^{(36,37)}$. Na formação médica, a capacidade de empatia dos profissionais por seus pacientes pode ser determinante no estabelecimento de uma boa relação médico-paciente ${ }^{(37)}$.

Compreender, portanto, os múltiplos sentidos e significados que o conceito de humanização pode assumir permite que, ao longo da formação, os estudantes possam vivenciar experiências que estejam pautadas também no princípio da integralidade do cuidado e da valorização do trabalho em equipe ${ }^{(15)}$. Dessa maneira, acredita-se que esse entendimento ampliado dos estudantes contribui para efetivação do que as $\mathrm{DCN}$ propõem como perfil desejável de médico, conciliando os saberes técnico-científicos, com habilidade de diálogo e capacidade de empatia com os outros. Algo também evidenciado nas seguintes falas:

"Um atendimento que acolha o paciente com as suas singularidades, que adeque o tratamento a cada caso particular e num ambiente que exista uma boa relação entre toda a equipe e pacientes." (Estudante 225, $3^{\circ}$ semestre)

"Atendimento humanizado é um atendimento integral, sob a luz de um conceito ampliado de saúde e processo de adoecimento, considerando os DSS e olhando o paciente de forma holística considerando seus aspectos de vida macro e micro sociais e individuais (genéticos e estilo de vida)." (Estudante 352, $2^{\circ}$ semestre)

"Atendimento médico humanizado é muito amplo, mas resumidamente é um atendimento que contemple o ser humano em sua totalidade, que considera não apenas aspectos biológicos do paciente, que visa não só a cura de doença e tratamento de sintomas, mas o bem-estar a longo prazo de pessoas." (Estudante $368,2^{\circ}$ semestre)

A capacidade de atuar em conjunto, respeitando as peculiaridades e saberes de cada profissão torna a interprofissionalidade uma proposta fundamental para a consolidação da proposta do SUS. Para tanto, autores argumentam que é fundamental que a formação dos profissionais de saúde tenha direcionamento baseado numa perspectiva crítico-reflexiva e interprofissional, de modo que se contribua para a transformação social dos sujeitos ${ }^{(38)}$.

Dessa maneira, é essencial reconhecer e valorizar as dimensões subjetivas dos usuários no atendimento( ${ }^{(39)}$. Não somente devido aos princípios éticos da profissão, mas porque essas pessoas são agentes sociais da própria mudança que deve ser alcançada através de reflexão consciente e compartilhada dos problemas entre eles e os profissionais e, também, do compartilhamento de saberes, em busca da melhor estratégia para solução das suas necessidades, o que na saúde é conhecido como empowerment. Uma percepção ampliada que também pôde ser percebida entre os estudantes:

"Anamnese bem feita, procurando saber do contexto social, cultural, religioso, econômico e entendendo acerca das desigualdades existentes, conhecendo o SUS e suas formas de acesso e que a terapêtica seja conversada, justa e beneficente, utilizando a ética." (Estudante 86, $1^{\circ}$ semestre)

"Um atendimento que considera um paciente em níveis complexos de saúde, não apenas biologicista ou reducionista, que empodera, ouve, intervém, auxilia e que promove uma relação horizontal de co-participação." (Estudante 442, $5^{\circ}$ semestre)

"É aquele que considera todas as dimensões do paciente e o enxerga como um todo, dando autonomia e empoderamento para ser participante do processo de cura e acompanhamento." (Estudante 425, $5^{\circ}$ semestre)

A PNH em seu texto afirma também que a ideia de humanizar inclui a oferta de atendimento de qualidade, de modo que se articule os avanços tecnológicos com outras demandas subjetivas dos pacientes, como o acolhimento, a melhoria dos ambientes de cuidado e ainda a melhoria das condições de trabalho dos profissionais de saúde ${ }^{(12)}$.

Corroborando essa definição, há evidências ${ }^{(35)}$ de que no modelo Humanista do cuidado em saúde, a competência profissional valoriza a técnica, contudo precisa ir além dela, porque o bom profissional exibe "traços humanísticos", além da "competência técnico-científica".

Finalmente, a terceira categoria reuniu as respostas que demonstraram concepções de humanização que, apesar de em alguns casos apresentarem aspectos que corroboram com alguns princípios da $\mathrm{PNH}$, transmitiram também uma ideia de superioridade médica e valorização de habilidades e conceitos técnicos em detrimento da boa relação médico-paciente, expondo uma contradição importante: 
"Um atendimento com excelência técnica e ao mesmo tempo, centrado no paciente, com o intuito de criar vínculos, empatia e todos os processos que facilitem a recuperação do paciente e visando diminuir taxa de desistências de tratamento/abandono de terapêutica." (Estudante 435, $5^{\circ}$ semestre)

"Respeitar a autonomia do paciente; Anamnese completa; Respeitar o Código de Ética Médica." (Estudante $152,1^{\circ}$ semestre)

"Atendimento médico humanizado é aquele que atenda às necessidades do indivíduo, sem prolongar nem abreviar demasiadamente por motivos pragmáticos." (Estudante 316, $7^{\circ}$ semestre)

É importante ponderar respostas como essas porque elas expõem pensamentos que reforçam o padrão hegemônico de supervalorização do modelo biomédico. Diante disso, é importante refletir que o objetivo do cuidado precisa ser o bem estar do paciente e não as expectativas de resultado dos profissionais e que as práticas precisam ser orientadas não só por evidências científicas, mas considerar também os aspectos culturais, socioeconômicos e subjetivos da relação médico-paciente ${ }^{(35)}$.

Em um estudo ${ }^{(3)} \mathrm{com}$ estudantes do curso de Medicina, os próprios alunos elegeram algumas características que seriam comuns entre os colegas, sendo elas a imaturidade emocional, os preconceitos (de raça, de sexualidade, de classe...), a alienação (quanto à noção de quem se é), competitividade, superficialidade e individualismo, e a falta de profissionalismo. Esse perfil gera preocupação não só por ter sido informado pelos próprios estudantes, mas, também, por se afastar completamente do perfil profissional preconizado pelas DCN e pela PNH. As autoras do referido estudo identificaram que o sentimento de superioridade é uma das principais características dos estudantes de medicina, apontada pelos próprios alunos, e para eles, isto seria uma conquista histórica, que demanda esforço para ser mantida. Algo que também ficou explícito em relatos desta presente investigação:

"É o que tem formação de vínculo e cuidado baseado nas evidências científicas como preconiza a medicina." (Estudante 231, $1^{\circ}$ semestre)

"É não achar que o paciente vai te processar e fazer uma medicina defensiva. E sim, ter uma boa comunicação e um olhar de cuidado, e se possível, atingir a "cura", no caso o paciente, ele se cura." (Estudante 174, $6^{\circ}$ semestre)

"Atendimento médico humanizado busca tratar o outro da forma que eu gostaria de ser tratado num momento de fragilidade, ter domínio satisfatório da técnica." (Estudante 187, $6^{\circ}$ semestre)

A valorização do modelo biomédico tecnicista, percebida nas falas anteriores, aliada a atual e persistente ideologia mercantilista da saúde contribui para essa realidade. Reconhece-se que as práticas relacionadas ao processo saúde-doença tem relação direta com os contextos social e cultural que elas estão inseridas e também com a maneira como os sujeitos vivenciam isso subjetivamente ${ }^{(39)}$. Portanto, esses aspectos não podem ser negligenciados durante o atendimento médico.

Na virada do século XX a importância do relacionamento entre médico e paciente foi dando lugar à necessidade de descoberta e rotulagem das doenças. Assim, o objetivo central do atendimento médico passou a ser a cura da doença. O poder atribuído aos médicos na contemporaneidade existe em decorrência do seu status profissional e da autonomia sobre seu trabalho, que é mantido por seu controle sobre o conhecimento médico. No entanto, esse conhecimento é construído em decorrência de uma luta de poder entre vários grupos de interesses diferentes, cada um com intenção de alcançar alto status e poder. Nessa esfera cita-se a indústria farmacêutica, meios de comunicação, a política, entre outros ${ }^{(3)}$.

Na contramão desse processo neoliberal e capitalista, o SUS foi criado com uma proposta de democratização do acesso à saúde, tendo como alguns de seus princípios norteadores a Universalidade, a Equidade e a Integralidade. Nesse contexto, cabe ainda acrescentar que a Humanização enquanto política pública, a partir de sua criação, passou a ser um eixo estruturante e transversal a todas as ações do SUS ${ }^{(12)}$. Diante disso, formar médicos capazes de atuar com excelência, implica também que estes compreendam o significado da Humanização, tanto do ponto de vista geral, enquanto política, quanto do ponto de vista micro, das relações cotidianas com pacientes e colegas de trabalho.

Em um estudo ${ }^{(40)}$ a respeito do olhar do estudante de Medicina sobre o SUS, analisou discursos de estudantes de vários semestres de 12 Instituições de Ensino Superior (IES). Um dado alarmante exposto nesta investigação foi o descontentamento da maioria dos estudantes com a ideia de atuar no SUS. Então, importou perceber que apesar de não ser o foco da pergunta, algumas respostas elucidaram o que pensam estudantes de medicina da UFBA sobre isso: 
"Atendimento médico humanizado é anamnese bem feita, procurando saber o contexto social, cultural, religioso, econômico e entendendo acerca das desigualdades existentes, conhecendo o Sistema Único de Saúde e suas formas de acesso e que a terapêutica seja conversada, justa e beneficente, utilizando a ética." (Estudante $86,1^{\circ}$ semestre)

Considerando-se tudo isso, um questionamento levantado durante o desenvolvimento desse estudo diz respeito a quais razões explicariam essas diferentes concepções de atendimento humanizado entre os estudantes, visto que todos vivenciam o mesmo curso. Um segundo questionamento, seria o de por que não houve grandes diferenças entre os semestres dos estudantes respondentes de cada categoria. Estar mais avançado no curso não foi fator determinante nas concepções de atendimento humanizado expressas por eles. Dado o exposto, ficou evidente a necessidade de se realizar novas e mais aprofundadas investigações, a fim de entender que outros fatores contribuem para o desenvolvimento dessas atitudes e a construção dessas concepções.

\section{CONSIDERAÇÕES FINAIS}

Esta investigação demonstrou a importância de se compreender o que pensam os estudantes de medicina da UFBA acerca da humanização visto que serão futuros profissionais de saúde, considerando as particularidades dos usuários e respeitando a dignidade humana. Sendo assim, observou-se que a partir das falas analisadas foram evidenciadas características em comum, que fizeram emergir a posteriori as categorias da investigação. Dessa maneira, as três categorias formadas agruparam respostas que demonstraram concepções de atendimento humanizado de acordo com os aspectos gerais que norteiam a PNH; outras com compreensões mais complexas, incluindo além das noções da política, aspectos subjetivos em suas respostas; e ainda falas que apontaram um conhecimento superficial a respeito do tema, além de uma tendência à valorização do modelo técnico-científico de atenção e da ideia de superioridade médica.

Diante do exposto, conclui-se que a formação do profissional de Medicina integra um processo mais amplo que inclui a mudança no modelo assistencial à saúde como também a formação de sujeitos comprometidos com as necessidades de saúde da população. Ademais, entende-se que a discussão sobre a formação deste profissional precisa passar pela incorporação de novos conteúdos e espaços de ensino-aprendizagem, nos quais a inclusão das humanidades, no processo histórico da educação médica brasileira, tem sido tensionada como uma estratégia efetiva de mudança na prática.

\section{AGRADECIMENTOS}

Ao CIAIQ, CAPES e CNPq.

\section{CONFLITOS DE INTERESSE}

Os autores declaram não haver conflitos de interesse

\section{COLABORAÇÕES}

Vitória Batista Calmon de Passos, Renata Meira Véras, Clara Fernandez, Odonilton Lemos participaram na concepção do estudo, na coleta e na análise/interpretação de dados, tiveram envolvimento na elaboração e revisão do manuscrito e aprovaram a versão final do manuscrito para publicação. Gustavo Cardoso e Marcelo Nunes Dourado Rocha participaram na elaboração e revisão do manuscrito e aprovaram a versão final do manuscrito para publicação.

\section{REFERÊNCIAS}

1. Barros MEB, Gomes RS. Humanização do cuidado em saúde: de tecnicismos a uma ética do cuidado. Fractal Revista de Psicologia. 2011;23(3):641-658.

2. Gomes RM, Schraiber LB. A dialética humanização-alienação como recurso à compreensão crítica da desumanização das práticas de saúde: alguns elementos conceituais. Interface Comunic. Saúde Educ. 2011;15(37):339-50. 
3. Rios IC, Schraiber L. Humanização e Humanidades em Medicina. São Paulo: UNESP, 2012.

4. Deslandes SF. Humanização dos cuidados em saúde: conceitos, dilemas e práticas. Rio de Janeiro: FIOCRUZ, 2006.

5. Brasil. Programa nacional de humanização da assistência hospitalar. Brasília: Ministério da Saúde. 2001, p.160.

6. Heckert ALC, Passos E, Barros MEB. Um seminário dispositivo: a humanização do Sistema Único de Saúde (SUS) em debate. Interface Communication, Health, Education. 2009;13:493-502.

7. Campos GWS. Um método para análise e co-gestão dos coletivos: a construção do sujeito, a produção de valor de uso e a democracia em instituições - o método da roda. São Paulo: Hucitec, 2000.

8. Filgueiras S. Eu não sou o HIV que eu tenho: humanização, acolhimento e escuta no atendimento a mulheres que vivem com Aids. In Deslandes, S (org.) Humanização dos cuidados em saúde: conceitos, dilemas e práticas. Rio de Janeiro: FIOCRUZ, 2006, p.389-414.

9. Teixeira RR. Humanização e Atenção Primária à Saúde. Ciência e Saúde Coletiva. 2006;10(3):585-597.

10. Amoretti R. A Educação médica diante das necessidades sociais em saúde. Revista Brasileira de Educação Médica. 2005;29(2):136-146.

11. Rios IC. Humanidades e medicina: razão e sensibilidade na formação médica. Ciência e Saúde Coletiva. 2010;15(1):1725-173.

12. Brasil. HumanizaSUS: Política Nacional de Humanização: a humanização como eixo norteador das práticas de atenção e gestão em todas as instâncias do SUS. Brasília: Ministério da Saúde, 2004, p.1-20.

13. Caprara A, Franco AL. Relação médico-paciente e Humanização dos cuidados em saúde: limites, possibilidades, falácias. In Deslandes, S (org.) Humanização dos cuidados em saúde: conceitos, dilemas e práticas. Rio de Janeiro: FIOCRUZ, 2006, p.85-108.

14. Rios IC. Humanidades e medicina : razão e sensibilidade na formação médica. Ciência e Saúde Coletiva. 2009;15(1):1725-1732.

15. Medeiros LMOP, Batista SHSS. Humanização na formação e no trabalho em saúde : Uma análise da literatura. Trabalho, Educação e Saúde. 2016;14(3):925-951.

16. Benevides R, Passos E. Humanização na saúde: Humanização na saúde: um novo modismo? Interface Comunicação, Saúde e Educação. 2005;9(17):389-394.

17. Nogueira-Martins MCF, Bógus CM. Considerações sobre a metodologia qualitativa como recurso para 0 estudo das ações de humanização em saúde. Saúde e Sociedade. 2004;13(3):44-57.

18. Haddad AE, Morita MC, Pierantoni CR, Brenell SL, Passarella T, Campos FE. Undergraduate programs for health professionals in Brazil: an analysis from 1991 to 2008. Revista de Saúde Publica. 2010;44(3):383-393.

19. González AD, Almeida MJ. Movimentos de mudança na formação em saúde: da medicina comunitária às diretrizes curriculares. Physis. 2010;20(2):551-570.

20. Funghetto SS, Silveira SM, Silvino AM, Karnikowski MGO. Perfil profissional tendo o SUS como base das Diretrizes Curriculares da área da saúde no processo avaliativo. Saúde em Redes. 2015;1(3):103-120.

21. Brasil. Ministério da Educação. Conselho Nacional de Educação. Câmara de Educação Superior. Resolução №. 3 de 20 de junho de 2014. Institui diretrizes curriculares nacionais do curso de graduação em Medicina e dá outras providências. Diário Oficial da União, Brasília, 23 jun. 2014; Seção 1, p.8-11.

22. Formigli VL, Barbosa HS, Lima MAG, Araújo IB, Fagundes NC, Macedo RSA. Projeto Político-Pedagógico do curso de graduação em medicina da FMB. Gazeta Médica Da Bahia. 2010;79(1):3-47.

23. Kerr LRFS, Kendall C. A pesquisa qualitativa em saúde. Rev Rene. 2013;14(6): 1061-1063.

24. Gil AC. Como elaborar projetos de pesquisa. São Paulo: Atlas, 2008.

25. Augusto CA, Souza JP, Dellagnelo EHL, Cario SAF. Pesquisa Qualitativa: rigor metodológico no tratamento da teoria dos custos de transação em artigos apresentados nos congressos da Sober (2007-2011). Revista de Economia e Sociologia Rural. 2013;51(4):745-764. 
26. Kronberger N, Wagner W. Palavras-chave em contexto: análise estatística de textos. In: Bauer MW, Gaskell G. (orgs.) Pesquisa qualitativa com texto: imagem e som: um manual prático. Petrópolis: Vozes. 2010; p.416-441.

27. Bardin L. Análise de conteúdo. Lisboa: Portugal: Edições 70;1977.

28. Campos CJG. Método de análise de conteúdo: Ferramenta para a análise de dados qualitativos no campo da saúde. Revista Brasileira Enfermagem. 2004;57(5):611-614.

29. Ferreira RA, Peret Filho LA, Goulart EMA, Valadão MMA. O estudante de medicina da Universidade Federal de Minas Gerais: perfil e tendências. Rev Ass Med Brasil. 2000;46(3):224-231.

30. Cardoso Filho FAB, Magalhães JF, da Silva KML, Pereira ISSD. Perfil do Estudante de Medicina da Universidade do Estado do Rio Grande do Norte (UERN), 2013. Rev Bras Educ Med. 2015;39(1):32-40.

31. Fiorotti KP, Rossoni RR, Miranda AE. Perfil do Estudante de Medicina da Universidade Federal do Espírito Santo, 2007. Rev Bras Educ Med. 2010;34(3):355-362.

32. Lima M. Desigualdades raciais e políticas públicas: ações afirmativas no governo Lula. Novos estudos. 2010;87:77-95.

33. Brasil. Caderno HumanizaSUS: Formação e intervenção. Brasilia: Ministério da Saúde, 2010, p.1-242.

34. Kumagai AK. From competencies to human interests: Ways of knowing and understanding in medical education. Academic Medicine. 2014;89(7):978-983.

35. Pereira RTMC. O ensino da medicina através das humanidades médicas: análise do filme And the band played on e seu uso em atividades de ensino/aprendizagem em educação médica [tese]. São Paulo: Universidade de São Paulo; 2004.

36. Rogers CR. The necessary and sufficient conditions of therapeutic personality change. Psychotherapy: Theory, Research, Practice, Training. 2007;44(3):240-248.

37. Costa FD, Azevedo RCS. Empatia, relação médico-paciente e formação em medicina: um olhar qualitativo. Revista Brasileira de Educação Médica. 2010; 34(2): 261-269.

38. Silva RHA. Educação interprofissional na graduação em saúde: aspectos avaliativos da implantação na Faculdade de Medicina de Marília (Famema). Educar em Revista. 2011;39:159-175.

39. Traverso-Yépez M, Morais NA. Reivindicando a subjetividade dos usuários da Rede Básica de Saúde: para uma humanização do atendimento. Cadernos de Saúde Pública. 2004;20(1):80-88.

40. Pereira GA, Stadler AMU, Uchimura KYO. O olhar do estudante de medicina sobre o sistema único de saúde: a influência de sua formação. 2018;42(3):57-66.

\section{Endereço para correspondência:}

Renata Meira Véras

Instituto de Humanidades, Artes e Ciências Professor Milton Santos da Universidade Federal da Bahia

Rua Barão de Jeremoabo, s/n

Bairro: Ondina

CEP: 40170-115 - Salvador - BA - Brasil

E-mail: renatameiraveras@gmail.com

\section{Endereço do primeiro autor:}

Vitória Batista Calmon de Passos

Instituto de Humanidades, Artes e Ciências Professor Milton Santos da Universidade Federal da Bahia

Rua Barão de Jeremoabo, s/n

Bairro: Ondina

CEP: 40170-115 - Salvador - BA - Brasil

E-mail: vitoria.passos17@gmail.com 